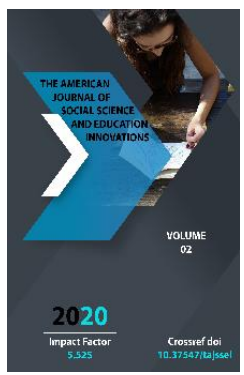

\title{
Specificity Of Student Creative Activity
}

\section{B. Imanov}

Candidate Of Pedagogical Sciences, Associate Professor, Head Of The Department Of Education Quality Control, Termez State University, Uzbekistan

Copyright: Original content from this work may be used under the terms of the creative commons attributes 4.0 licence.

\section{ABSTRACT}

This article explores the components of a student's creative abilities, descriptions of each, in performing a problematic experiment in physics.

\section{KEYWORDS}

Comparison, logic, dream, intuition, discovery.

\section{INTRODUCTION}

If the specificity of a student's creative activity is analyzed from a pedagogical point of view, it can be immediately apparent that there are currently no common criteria for defining this concept. The results of the study of psychological, pedagogical and didactic literature allow us to reveal its content and show that it has a number of features.
M.I.Makhmutov,A.I.Matyushkin,T.V.Kudryavts ev give material experience and assignments. V.G.Razumovsky, D. Poya, Yu.N. Kulyushkin, V.I.Andreev suggest that creative activity is aimed at solving educational problems.

V. I. According to Andreev, Yu.N. Kulyushkin, AF Esaulov, creative activity is a pedagogically 
controlled activity, but pedagogical management is promising and direct.

Management of student creative activity is based on the third type of direction.

Yu.N.Kulyushkin. In the research work of V.I.Andreev, L.M.Friedman, I.P.Koloshny and others, heuristic programs and general guidelines are substantiated.

The success of creative activity depends not only on the level of formal, logical development, but also on the intellectual intuitive-heuristic (not always understood) movements,- said Ya.A.Ponomaryov, O.K.Tixomirov, Yu.N.Kulyushkin and others.

\section{THE MAIN FINDINGS AND RESULTS}

One of the important features of creative activity is the new qualities that emerge as a result of its implementation: knowledge, skills, creative ability of the reader, thus different authors point to different organizers of new qualities. For example, L.S.Vygotsky, S.L.Rubinstein focus on the acquisition of new knowledge in the process of performing problematic experiments in the creative activity of the student.Ya.A. Ponomaryov, Yu.N. Kulyushkin show the birth of new goals and objectives, A.N. Leontev, O.K.Tikhomirov demonstrate new methods and knowledge of activity as a basis for activity.

So, each of the authors is unquestionably true, but the psychic new qualities mentioned, though correct, are not complete enough. Psychological qualities should take into account, first of all, the development of the creative ability of the student, the reasons for its founders, the development of intellectual worldview, spiritual, communicative, aesthetic and other qualities. They occur during the student's creative activity and are activated in the process of its implementation.

Thus, creative activity is a type of learning activity, which is subjective innovation, significant and progressive in the development of creative abilities of students, activities aimed at performing problem-solving experiments in physics in the context of the use of promising or direct pedagogical management tools for maximum use of student self-management.

Now we will compare the following three types of creative activity: student, creative activity, scientific and scientific-creative activity of the scientist, it is necessary to keep in mind the results of the comparison when talking about the student's activity, especially his creative activity.

The following are the types and manifestations of student creative activity:

The activity can be in the following order according to the intuitive and logical learning structure:

a) intuitive-heuristic;

b) normative, logical-creative activity.

In this regard, IA Kaloshina draws attention to the fact that "creative activity, which is carried out empirically without trial and error, is a possible path."

It is a creative activity that is carried out in a theoretical way, understood in a way that moves from abstraction to precision. Such creative activity is called normative activity, or more precisely, the normative intellectual component is called creative activity.

Depending on the nature of the content of the problem experiment, the following may be indicated: 
a) inventive activity;

b) research activities;

c) artistic activity (music, visual activity), practical creative activity (folk handicrafts).

Theoretical and empirical ratios of creative activity can be shown:

Depending on the level of creativity in setting and performing a challenging experience:

a) independent creativity;

b) mandatory creativity.

According to the logical order and proportion of the student's creative activity:

a) inductive creativity;

b) deductive creativity.

Depending on the objective and subjective ratio of the importance of the field (level of activity) and the novelty of the result:
a) creative;
b) scientific (or simple creation).

Depending on the field of subjectivity:

a) mathematical creativity;

b) physical creation;

c) artistic creation, etc.

Depending on the form of organization of communicative relations:

a) individual;

b) partnership;

c) grouped;

d) as a team.

The concept of "creative reader" has long been used in the literature on philosophy, psychology and pedagogy. For example, in the book "Creative reader and the environment in the field of technical inventions" by the Russian scientist LK Engelneyer, we come across the idea that "Creative reader is a progressive element that creates innovation."

The Russian philosopher A.N. Luke "Although he did not define the concept of the creative reader, but he widely used this concept and pointed out its features:

a) preparation for risk;

b) Independent, impulsive and critical thinking (independent student in school) sometimes expresses attitude towards the teacher. He decides which science to pursue;

c) I.P.Pavlov argues that the mastery of academic subjects is not uniform, if a student masters one or two academic subjects well and others poorly, it forces him to pay attention; it suggests whether it is talent;

d) Humor and understanding of humor;

e) Originality;

f) Mobility to learn in depth;

g) Boldness of imagination and thought.

"He emphasizes that the main quality of a creative student is courage. AN Luke is a gifted student of intellect, will, and courage. "It should be noted that a creative reader, he is not really afraid of conflicts with the surrounding reality. One of the characteristics of a creative reader is courage.

American sociologist D.J. Becker examines the problem of creative ability and intelligence of the reader and describes an intelligent person as follows. "He was born with a great creative imagination, original thinking, ingenuity, the ability to innovate, and these views confirm the notion of an intelligent person against the imitation of traditions and obedience to rules." 
We can continue to talk about the creative ability of other authors to read. But a different approach, in our opinion, would be interesting. This is the way from the general to the specific. The methodology of solving complex problems directs us from the analysis of the general to the study of the specific, to examine it.Great scientists, writers, the military studied the biographies of creative students, understood them, and came to this conclusion.

A creative learner is one who has more than one type of activity or one type of activity. The creative reader can be described more broadly. A creative student is a student who is active because he or she strives for a strong, high level of creativity. They are manifested in organic unity and a high level of creative ability, which allows them to achieve advanced social, personal and creative results. Often a creative learner succeeds in one type of activity. For example, music, sports, physics, mathematics, chemistry, biology, etc. But in history, there have been people who have succeeded in several activities. It is therefore appropriate to speak of a comprehensively developed creative reader.

We will now describe some of the categories and appearances of the creative reader below:

I. Kant: "Shows the types of human intelligence genius, talent, diligence: genius, talent, balance." In the literature on creative student psychology shows more thinking and artistic types. They were proposed by IP Pavlov: "Life clearly shows two types of people - the artist and the thinker." There is a sharp difference between them. The first is that the artist, the artist, accepts the truth as it is, without breaking it into pieces.

Other thinkers, on the other hand, divide them into tiny pieces, temporarily making a skeleton out of them, and then slowly collect it again from the pieces, thereby reviving it. This does not always give a complete result.However, the separation of the reader into creative and art critics is conditional. Antoine de SaintExupery describes it with his unique poetic skill: "He believes in theory, in logic. He thinks it does not take into account dream, intuition and poetry. They change the clothes of these three angels and do not realize that they are trying to seduce him on horseback. He does not know that these three angels should be grateful for his wonderful discoveries. They are referred to as "working assumptions," "free imagination," "analogies," and the theorist does not know that he is listening to them, going against strong logic, and following inspiration."

Now let's focus on the possibility of dividing creative students into three categories. The theory-logician is a creative reader of this category, which is characterized by a wide range of logical generalizations, variations, systematization of data. Such a student clearly plans his creative activity. It makes extensive use of previously known scientific research.

Such students become aware and knowledgeable of everything, based on previously known theoretical concepts and further develop them. Theoretical-intuitive This category of creative students is characterized by the development of new ideas, highly developed abilities. This category of creatively gifted students will be great inventors, creators of new scientific concepts, and creators of scientific schools. There are sometimes unrecognized "talents" among them, but such students are not afraid to oppose their ideas to the generally accepted order, and this type of student has a very broad vision. Practitioner - This category of creative students always strives to test their new scientific ideas in practice. Such students love to work in an experimental setting. It is often said of experimenters that "his hands are 
golden." To an educational institution - this category of creative students will be highly capable of developing new ideas, organizing others and the team to put them into practice. Under the guidance of this category of students, excellent scientific schools and creative teams are formed. Such a student excels in high diligence, communicativeness, in subjugating others to his will, that is, in directing him to perform a problematic experiment.

Initiative - this category of students is characterized by constant mobility. They work tirelessly to accomplish a new challenging experience. They say about this category of students, "Does he need it more than anyone else?" Their diligence and creative initiative are admirable. But usually, they quickly become inactive and begin to experiment with other new creative content.

Creative activity consists of the following stages of development:

In the first stage of development, the student is characterized by a strong interest in a particular creative activity for obvious reasons. This stage can be conditionally called the creative direction selection stage because the student chooses a specific activity. At this stage of development, the student seems to intuitively feel in which field of activity he can fully express himself. For example, preschoolers are more likely to draw or make something in their spare time than in other activities. can be called activity. This stage is more specific to middle and older students.

The third stage of development is characterized by high professional-creative activity of the student with a specific type of activity. Intuitive creative mastery of specialization methods, techniques and tools specific to this type of activity is observed for this type of stage. these movements are especially evident in artists, musicians, athletes, who express themselves as a stage of mastering the practice of professional activity with creative activity.The fourth stage of development can be expressed as the stage of the first creative achievements of the student. If we look at the inventor, then the great independent discovery is the first book to be recognized and successful for the writer.The fifth stage of development signifies the highly stable creative productivity of the reader. The activity and skill for this stage is characterized by the formation of an individual creative method.

Psychological aspects of this problem have been widely studied, analyzed and generalized, using scientific research, monographs, teaching aids of foreign and Uzbek psychologists.

1. As a result of the analysis of the creation of problem situations in the performance of problem experiments in physics, three approaches - psychological, epistemological, didactic, as well. In the psychological approach, the classification of the problematic situation on three grounds is highlighted.

2. Types of creative abilities of students and their characteristics in the performance of problem-solving experiments in physics are analyzed. The components of the student's physical ability are also substantiated.

3. The components of a student's creative ability in performing a problem experiment are described, each with a description.

4. Methodology for pedagogical assessment and self-assessment of students' creative abilities in problem-solving has been developed. In doing so, it focuses primarily on the logical fit of the learning process. Therefore, along with special pedagogical observations, the use of a five-point system 
in performing and evaluating a diagnostic problem experiment in physics was reflected.

5. The types and manifestations of the student's creative activity in the performance of the problem experiment are given, and their features are shown.

\section{REFERENCES}

1. Appendix 1 to the Resolution of the President of the Republic of Uzbekistan dated 08.10.2019 №5847 "Concept of development of the higher education system of the Republic of Uzbekistan until 2030".

2. Decree of the President of the Republic of Uzbekistan PF-5535 dated 05.09.2018 "On additional measures to improve the management system of public education."

3. Rubenstein S.L.Problemy obshchey psychologii. - M .: Pedagogy, 1976.

4. Simonov V.P.Diognostika stepeni obuchennosti uchashixsya, - M .: 199-206 s.

5. NI Amirov Problems and effective ways of developing creative qualities in teachers, 2018. 